\title{
OS ÊXITOS E OS LIMITES MORAIS DO UTILITARISMO DE BENTHAM: UMA ABORDAGEM A PARTIR DE SANDEL
}

\author{
[The Successes and the Moral Limits of Benthamian Utilitarianism: an APProach \\ ACCORDING TO SANDEL]
}

\author{
Francisco Jozivan Guedes de Lima* \\ Universidade Federal do Piauí, Brasil \\ Everton Miguel Puhl Maciel ** \\ Universidade Federal do Amapá, Brasil
}

\begin{abstract}
Resumo: Este artigo pretende apresentar a partir de Sandel as teses fundamentais do utilitarismo de Bentham destacando seus aspectos vantajosos e seus déficits do ponto de vista moral. $\mathrm{O}$ aspecto deficitário do utilitarismo benthamiano diz respeito à violação do indivíduo à medida em que lhe é demandado o sacrifício em prol do bem-estar da maioria; além disso, há também o problema da uniformização dos valores e dos prazeres. No que concerne aos êxitos do utilitarismo sugere-se o descentramento do racionalismo a partir do binômio prazer e dor e, com isso, a ampliação da proteção ética e legal de animais não-racionais, porém sencientes.
\end{abstract}

Palavras-chave: Bentham. Déficit. Êxito. Sandel. Utilitarismo.

\begin{abstract}
This paper aims to present according to Sandel the fundamental theses of utilitarianism of Bentham highlighting its advantageous aspects and its deficits from the moral point of view. The deficit aspect of Benthamian utilitarianism concerns the violation of the individual to the extent that the sacrifice for the welfare of the majority is demanded of him; in addition, there is also the problem of standardization of values and pleasures. Regarding the successes of utilitarianism, we suggest the decentering of rationalism from the binomial of pleasure and pain, and with it, the extension of the ethical and legal protection of non-rational yet sentient animals.
\end{abstract}

Keywords: Bentham. Deficit. Success. Utilitarianism.

\section{INTRODUÇÃO - UMA CONJECTURA SOBRE TRÊS ELEMENTOS ESSENCIAIS DO UTILITARISMO}

A natureza colocou o gênero humano sob o domínio de dois senhores soberanos: a dor e o prazer. Somente a eles compete apontar o que devemos fazer, bem como determinar o que na realidade faremos

(Bentham, Uma introdução aos princípios da moral e da legislação, cap. I).

\footnotetext{
* Professor do Programa de Pós-Graduação em Filosofia/PPG e do Departamento de Filosofia da Universidade Federal do Piaui-UFPI. Doutor em Filosofia pela Pontíficia Universidade Católicado Rio Grande do Sul-PUCRS.m@ilto: jozivan2008guedes@gmail.com.**Professor no Colegiado do Curso de Licenciatura em Filosofia da Universidade Federal do AmapáUNIFAP. Doutor em Filosofia pela Pontifícia Universidade Católica do Rio Grande do Sul PUCRS.m@ilto: jornalistamaciel@gmail.com
} 
Waria Cecília de Carvalho (2000, p. 100ss) num artigo em defesa do utilitarismo publicado no livro Correntes fundamentais da ética contemporânea organizado pelo professor Manfredo de Oliveira (UFC/Brasil), articula três concepções filosóficas básicas de utilitarismo ${ }^{1}$, a saber, (i) as teorias mentalistas do bem-estar que na sua versão clássica em Bentham e Mill entende que a utilidade (maximizar o prazer e minimizar a dor) é compatível com um estado mental dos indivíduos; (ii) as teorias do bem-estar focadas nas preferências dos indivíduos que têm como um dos seus expoentes Amartya Sen²; (iii) e as teorias objetivistas do bemestar que refutam a ideia de mentalismo e de preferência e submetem o útil (aquilo que causa prazer) a uma lista objetiva de itens que promovem a felicidade.

No início de seu artigo, a autora conjectura que há diversos espectros de utilitarismo - como os supra-apresentados e podem haver mais - e que aparentemente não há uma essência comum a eles. Entretanto, pensamos que é possível encontrar alguns traços essenciais comuns nas diversas versões do utilitarismo, traços estes que remontam à sua versão clássica em Bentham a partir de An Introduction to the Principles of Morals and Legislation (1789). Se não tivermos em vista estes elementos essenciais, correremos o risco de estarmos falando não de utilitarismos afins, mas de coisas diferentes.

Dentre esses traços essenciais comuns podem-se conjecturar três ${ }^{3}$ : (i) a associação entre utilidade e felicidade; (ii) o afastamento do formalismo deontológico e a consequente métrica teleológica da ação moral instanciada a partir do consequencialismo ${ }^{4}$; (iii) um descentramento do especismo e, ipso facto, uma ampliação da proteção ética com vistas a inclusão dos animais não-racionais, todavia sencientes, isto é, capazes de sentir prazer e dor tal como apresentada por Peter Singer na sua reivindicação de uma igualdade de proteção para animais. Tencionando ratificar essa linha argumentativa da defesa de elementos essenciais das diferentes versões utilitaristas, encontra-se logo na introdução de Utilitarianism and Beyond (1982, p. 3ss) feita por Amartya Sen e Bernard Williams afirmações segundo as quais os pressupostos do bem-estar (Welfarism) e do consequencialismo (Consequencialism) são tidos enquanto características basilares do utilitarismo.

A título de introdução, não se pode abrir mão desta base comum que perpassa os vários vieses utilitaristas, a saber, $(\alpha)$ a imbricação entre utilidade e felicidade, $(\beta)$ o afastamento do formalismo deontológico de matriz kantiana e a adesão a uma ética focada em fins e balizada pelas consequências das ações, $(\gamma)$ e a ampliação da proteção ética para além do racionalismo e do especismo incluindo, destarte, os animais sencientes e não-racionais no rol da referida proteção. Esses três elementos introdutórios da filosofia utilitarista acompanharão o rumo das discussões ao longo deste artigo, todavia com um recorte a partir da apreciação de Michael Sandel no seu livro Justice.

\section{Dois esclarecimentos prévios sobre o utilitarismo: BenthaM, Mill e ARISTÓTELES}

Antes, porém, de adentrar propriamente na abordagem sandeliana acerca do utilitarismo tencionaremos esclarecer dois pontos que julgo cruciais: (i) uma distinção prévia entre o utilitarismo de Bentham e Mill a fim de não colocarmos ambas as versões num pacote utilitarista homgêneo; (ii) e uma distinção também en passant, porém

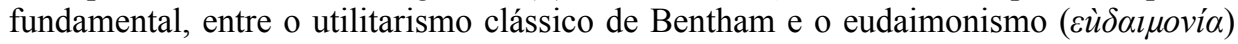
aristotélico, com intuito de desmitificar uma imbricação total entre ambos os espectros 
como se o primeiro derivasse in toto do segundo já que ambos focam na felicidade como conceito central.

Quanto ao primeiro ponto, Mill, semelhante a Bentham, defende um utilitarismo hedonista, "hedonista" no seu sentido amplo vinculado à felicidade, àquilo que traz

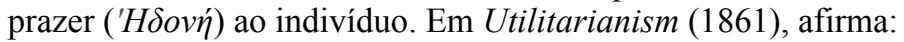

A crença que aceita como a fundamentação da moral, a utilidade, ou o maior princípio da felicidade, sustenta que as ações são corretas na medida em que tendem a promover felicidade, e erradas quando tendem a produzir o contrário da felicidade. Por felicidade é entendido o prazer, e a ausência de dor; por infelicidade, dor e a privação do prazer (MILL, 2009, p. 14, tradução minha) ${ }^{5}$.

Todavia, pensamos que a diferença entre ambos é que Mill insere a liberdade como uma categoria central dentro da filosofia utilitarista, de modo que há um redimensionamento e uma nova perspectiva do utilitarismo benthamiano pensado como mero cálculo de maximização de prazer para o maior número de pessoas. Ou seja, a categoria liberdade traz consigo a preocupação com a ressalva e o resguardo da individualidade, a fim de que esta não seja reprimida de modo drástico pelo cômputo da felicidade da maioria. Essa abordagem mais individualizada do utilitarismo fez com que Mill em The Subjection of Women (1869) desse uma atenção mais destacada a dadas categorias que viviam em contextos de repressão, como é o caso do seu olhar especial para questionar a situação de inferioridade das mulheres e a sua subordinação androcêntrica, algo que para ele não tinha razão de ser e impedia o progresso individual e coletivo além de prejudicar a liberdade feminina. A partir de Mill, os esforços da tradição liberal ficaram concentrados em ampliar o respeito às liberdades individuais, por um lado, e conjugar esse cenário com a maximização do bem-estar social, algo que excedeu os limites do utilitarismo benthamista. Contudo, mostraremos a seguir, ele deu nova roupagem para o princípio da utilidade, mesmo se mantendo fiel aos três eixos centrais da corrente: combate ao especismo, teleologia consequencialista, e fundamento na felicidade.

Por detrás dessa preocupação milliana esconde-se a preocupação com os riscos da "tradição" legitimar abusos que impedem o progresso da razão e da utilidade: "de todas as dificuldades que impedem o progresso do pensamento e a formação de opiniões bem fundamentadas acerca da vida e de arranjos sociais, o maior é a então indizível ignorância e desatenção da humanidade em relação às influências que formam o caráter humano" (MILL, 2009, p. 40) ${ }^{6}$. Deve-se, portanto, ter o máximo de cuidado a fim de que o hábito e a tradição não constituam per se a base normativa de ethos, pois poderá ocorrer que legitimem práticas excludentes dentro de uma dada sociedade.

O outro ponto básico que precisa ser elucidado é a relação entre o utilitarismo de Bentham e o eudaimonismo ${ }^{7}$ de Aristóteles, pensados como éticas da felicidade ou do bem-estar. Embora tenham um esteio comum - a ideia de felicidade - são distintos em dois sentidos: (i) a felicidade ${ }^{8}$ em Aristóteles é pensada num plano ético-ontológico enquanto telos existencial dos indivíduos racionais, e em Bentham é pensada em termos pragmáticos e utilitários instanciando-se como um cômputo que tenciona a maximização do prazer e a minimização da dor; (ii) a outra diferença é o conceito de razão subjacente a ambos os modelos éticos, pois na ética das virtudes de Aristóteles a razão ( $\lambda o ́ \gamma o \varsigma)$ é pensada em termos fortes como a base da ação e a condição para o êxito que consiste em chegar a mediania entre o excesso e a carência; há, ipso facto, um racionalismo na qual a virtude é posta como a capacidade do $\log o s$ de determinar o pathos ( $\rho a ́ \theta o \varsigma)$, algo que entrou na tradição filosófica latina como a capacidade da ratio determinar a voluntas. 
Em Bentham, a razão é um meio para um determinado fim (a utilidade); ela é, por isso, um instrumento usado para a operacionalização de um cálculo custo-benefício - é uma razão mitigada comparada a de Aristóteles. Bentham é avesso ao racionalismo e expande os limites da ética para além da razão, ancorando-se na sensibilidade, na defesa de seres sencientes, e em termos de ética prática repudiaria o especismo aristotélico e o da tradição subsequente. Enquanto a felicidade para Aristóteles é um telos eminentemente humano de seres racionais, para Bentham a felicidade é ampliada para todos os seres sejam eles racionais ou não-racionais - o que conta é que sejam sencientes, isto é, capazes de sentir dor e prazer mesmo que em sua dimensão somática (corpórea): "a natureza colocou o gênero humano sob o domínio de dois senhores soberanos: a dor e o prazer. Somente a eles compete apontar o que devemos fazer, bem como determinar o que na realidade faremos" (BENTHAM, 1979, p. 3).

\section{O UTILITARISMO DE BENTHAM SEGUNDO SANDEL: ALGUNS EXEMPLOS DE VIOLAÇÃO DE DIREITOS INDIVIDUAIS}

Sandel dedica o segundo capítulo do seu livro Justiça a explorar o utilitarismo de Bentham a partir de alguns dilemas morais, tencionando demonstrar, sobretudo, as suas limitações. Eis como Sandel introduz o utilitarismo benthamiano:

Sua ideia central é formulada de maneira simples e tem um apelo intuitivo: o mais elevado objetivo da moral é maximizar a felicidade, assegurando a hegemonia do prazer sobre a dor. De acordo com Bentham, a coisa certa a fazer é aquela que maximizará a utilidade. Como 'utilidade' ele define qualquer coisa que produza prazer ou felicidade e que evite a dor ou o sofrimento (SANDEL, 2014, p. 48).

Uma consulta ao próprio Bentham ratifica a definição supracitada de Sandel:

Por princípio da utilidade entende-se aquele princípio que aprova ou desaprova qualquer ação, segundo a tendência que tem a aumentar ou a diminuir a felicidade da pessoa cujo interesse está em jogo, ou, o que é a mesma coisa em outros termos, segundo a tendência a promover ou a compreender a referida felicidade. Digo qualquer ação, com o que tenciono dizer que isto vale não somente para qualquer ação de um indivíduo particular, mas também de qualquer ato ou medida de governo (BENTHAM, 1979, p. 4).

Isso demonstra que, para Bentham, o utilitarismo ${ }^{9}$ tem uma implicação normativa tanto para agentes morais singulares quanto para legisladores políticos, de modo que a maximização da felicidade deve ser um objetivo de indivíduos e instituições tendo em vista o alcance do maior número de pessoas e a comunidade. E o que entende Bentham por "comunidade"? "A comunidade constitui um corpo fictício, composto de pessoas individuais que se consideram como constituindo os seus membros. Qual é, neste caso, o interesse da comunidade? A soma dos interesses dos diversos membros que integram a referida comunidade" (BENTHAM, 1979, p. 4).

Essa perspectiva somatória do utilitarismo aplicado a questões concernentes à comunidade e à política pode ser profundamente problemática porque na operacionalização da soma de interesses pode deixar de fora e obliterar partes e grupos que não endossem a proposta de uma maioria ocasionando, desta forma, certa imposição de um grupo majoritário sobre uma minoria. Foi justamente contra esse cômputo utilitarista aplicado a questões de governabilidade que Kant se voltou na sua crítica àquilo que no seu tempo (no século XVIII) era chamado de "democracia".

Entre as três formas de Estado, a democracia, no sentido próprio da palavra, é 
necessariamente um despotismo, porque ela funda um poder executivo onde todos decidem sobre e, no caso extremo, também contra um (aquele que, portanto, não consente), por conseguinte todos que não são, contudo, todos, o que é uma contradição da vontade geral consigo mesma e com a liberdade (KANT, 2010, p. 28).

Passemos agora a alguns dilemas. (i) O dilema dos sobreviventes em alto mar. $\mathrm{O}$ primeiro dilema colocado por Sandel para tratar do utilitarismo é o dos marinheiros ingleses à deriva num pequeno bote salva-vidas a mais de $1.600 \mathrm{~km}$ da costa no Atlântico Sul. No bote havia quatro homens: Dudley o capitão, Stephens, Brooks, e Parker um novato de 17 anos. Depois de 19 dias à deriva, o capitão sugeriu fazer um sorteio para ver quem seria sacrificado para que os demais sobrevivessem, porém Brooks rechaçou a proposta. Mas havia uma saída: Parker, contrariando recomendações dos mais experientes, bebeu água salgada e adoeceu; como uma forma de apressar a sua morte e amenizar o seu sofrimento, foi sacrificado com um corte de canivete na jugular. "Durante quatro dias, os três homens se alimentaram do corpo e do sangue do taifeiro" (SANDEL, 2014, p. 46). Esse caso obviamente gera algumas interpelações para a filosofia moral, a saber: há moralidade e legalidade em casus necessitatis? Quais os limites éticos do ser humano? Os que sacrificaram Parker em vista da sobrevivência deveriam ser inocentados? A moralidade esbarra no bem-estar e na utilidade? Não se busca aqui com essas questões dar respostas, mas apenas colocar os problemas para a reflexão.

(ii) O dilema do bonde desgovernado. Este dilema não é originalmente de Sandel, mas da filósofa britânica Philippa Foot e está no artigo "The Problem of Abortion and The Doctrine of the Double Effect" publicado na Oxford Review (n. 5:1967). Você está na condução de um bonde desgovernado e imparável a quase 100 $\mathrm{km} / \mathrm{h}$ : se continuar reto você matará cinco operários que estão trabalhando nos trilhos; resta-lhe uma opção, desviar para outro trilho e matar um operário. O que fazer? Deixar o bonde seguir sua ordem e matar os cinco ou sacrificar um pela maioria? Como o utilitarismo que preza pelo bem-estar da maioria resolveria esse dilema? Sacrificando um indivíduo do trilho alternativo? Quão assassino você se sentiria se desviasse para o único indivíduo? Quão herói se sentiria em salvar os cinco mesmo que em detrimento do um?

(iii) $O$ dilema dos pastores afegãos. O dilema agora não é fictício como o anterior, mas real; aconteceu em junho de 2005 e foi retratado pelo suboficial Luttrell (também retratado no filme $O$ grande heró $i^{10}$ ). Quatro soldados norte-americanos (estadunidenses) estão no Afeganistão na fronteira com o Paquistão em busca de um líder talibã ligado a Osama Bin Laden. Avistam dois camponeses tangendo cabras e junto com eles uma criança; pareciam estar desarmados, mas surgiu o medo de que, se ficassem soltos, poderiam delatar aos talibãs a localização da patrulha. Não havia cordas para amarrá-los e a questão era: matar ou deixá-los ir? E se fossem apenas meros pastores inocentes? A decisão final (o voto de minerva) coube a Luttrell e este, alegando falar mais alto nele a alma cristã, decidiu deixá-los ir porque seria cruel matá-los a sangue-frio. Aproximadamente uma hora e meia depois, em torno de cem talibãs armados com fuzis e granadas os encontram e matam os três companheiros de Luttrell e apenas ele sobrevive gravemente ferido. Além dos três soldados, outros dezesseis que vieram prestar apoio em helicóptero também foram mortos. Luttrell se arrependera profundamente da decisão tomada (apesar de que poderíamos dizer a ele que não há provas de que o motivo da morte de seus colegas foi, de fato, a delação dos pastores).

(iv) A cidade da felicidade. Trata-se de um dilema extraído por Sandel (2014, p. 54) de um conto de Ursula K. Le Guin: The Ones who Walked Away from Omelas. A 
cidade da felicidade - como o próprio o nome o diz - é plena: não há corrupção, impostos extorsivos e abusivos, escravos, ameaça planetária alguma (e outros itens a mais que se queria elencar), tudo é perfeito. Mas ela é feliz em detrimento de uma criança oligofrênica que é mantida num porão com porta trancada e sem janelas, portanto excluída do convívio social. Se a criança fosse colocada em convívio com os demais membros da cidade, já não haveria mais felicidade (ar puro, boas colheitas, céu bonito...). O exemplo colocado por Sandel é justamente para demonstrar a falha do utilitarismo de Bentham ao maximizar o prazer para o maior número em detrimento da minoria afetada, como segue no caso abaixo.

(v) Um reformatório para mendigos. De acordo com Sandel (2014, p. 49), isso foi uma ideia de Bentham com a finalidade de melhorar o tratamento para com os pobres que viviam nas ruas e também para aumentar a utilidade coletiva, isto é, a felicidade da maioria. A ideia partia da percepção que os mendigos nas ruas causavam dois sentimentos que prejudicavam a utilidade daqueles que os viam abandonados, a saber: o sentimento de pena naqueles mais sensíveis, e o nojo nos mais insensíveis. Nesse sentido, a fim de promover a felicidade da maioria, Bentham propôs que estes mendigos fossem levados para um "reformatório" onde pudessem ser cuidados, pudessem trabalhar e ter uma vida digna, e isso seria mantido pelo próprio mendigo através de seu trabalho. Os cidadãos que capturassem um mendigo e levassem-no para o reformatório receberiam um incentivo financeiro que seria pago pelo próprio mendigo.

Alguns podem considerar isso injusto com os mendigos, mas Bentham não negligencia a sua 'utilidade' (felicidade). Ele reconhece que alguns mendigos seriam mais felizes mendigando do que trabalhando em um abrigo, mas observa também que para cada mendigo feliz mendigando existem muitos infelizes. $\mathrm{E}$ conclui que a soma do sofrimento público em geral é maior do que a infelicidade que os mendigos levados para o abrigo possam sentir (SANDEL, 2014, p. 50).

Como resolver o problema em questão: deve ter prevalência o bem-estar da coletividade com a condução de mendigos para reformatórios, condução esta contra a vontade dos mesmos, ou deve prevalecer o querer individual de mendigos que se recusam a deixar as ruas não lhes importando ojeriza, pena ou qualquer outro sentimento da coletividade em relação a eles? São casos concretos e polêmicos com os quais convivemos em nosso cotidiano - o exemplo da "cracolândia" em São Paulo é um deles em que esta tensão vem à tona.

(vi) Jogando cristãos aos leões. Sandel reporta-se à Roma, ao Coliseu, onde cristãos eram atirados aos leões e dilacerados enquanto a multidão se divertia. Como resolver isso do ponto de vista do utilitarismo? Se os cristãos em sofrimento são minoria e, no outro lado da balança, os que se divertem com o seu sofrimento são maioria, sob a ótica do cálculo utilitarista da maximização de prazer para o maior número, tal prática seria então legítima? Nas palavras do próprio Sandel (2014, p. 51), "se a quantidade de romanos que se deleitam com o espetáculo for muito maior do que a de cristãos, que argumentos teria um utilitarista para condenar tal prática?" Como resolver a tensão entre a utilidade do indivíduo que sofre e a utilidade da coletividade que se deleita com o seu sofrimento? Qual deve ter mais peso à luz do utilitarismo clássico de Bentham? O que Sandel defende em Justiça é que esse é o ponto fraco de Bentham, a saber, a violação de direitos individuais a partir de um cálculo utilitário onde o bem-estar da maioria é o escopo central.

(vii) O perigo da subsunção da ética à métrica do custo-beneficio - os benefícios do câncer de pulmão. O caso reportado por Sandel (2014, p. 56) aconteceu 
na República Tcheca envolvendo a Philip Morris International (companhia de tabaco e seus derivados) e o governo local que, tendo em vista o aumento de gastos públicos com cuidados médicos de pessoas doentes por consequência do fumo, resolveu elevar os impostos sobre cigarros. A Philip Morris tentando barrar a elevação de impostos encomendou um estudo de custo-benefício do tabagismo no orçamento público. $\mathrm{O}$ resultado foi o de que o governo mais lucra do que perde com o tabagismo, pois as pessoas, sobretudo as com câncer de pulmão, morrem mais cedo e isso faz com que o governo economize recursos com aposentadorias, abrigos para idosos, e outros gastos públicos para pessoas com idade avançada. Em síntese, na ótica da pesquisa encomendada pela P. Morris, o fumo traz mais benefícios do que custos ao governo e por isso não era legítimo aumentar as taxações sobre cigarros. Eis o perigo da aplicação do cômputo utilitarista do custo-benefício em nível de mercado e em casos práticos da vida: a violação da moralidade. Isso demonstra que o utilitarismo em nível pragmático de aplicabilidade não é tão atraente do ponto de vista moral, como se pensa. Com a pressão dos antitabagistas e a celeuma causada pela lambança da P. Morris, foi necessário que a multinacional se recompusesse e apresentasse suas desculpas ao povo tcheco.

(viii) O dilema da Lei de Segurança Aérea na Alemanha. Este dilema não é de Sandel nem reportado por ele, mas extraído de Sobre a constituição da Europa (Zur Verfassung Europas, 2011) de Habermas. Em 2006, cinco anos depois dos ataques de 11 de setembro de 2001, O Parlamento alemão tinha votado a favor desta Lei que permitia o abate de aviões com terroristas e civis, pois era necessário sacrificar uma minoria no ar para salvar uma maioria em solo. O Tribunal Constitucional Federal da Alemanha deliberou pela inconstitucionalidade da "Lei de Segurança Aérea" sob a justificativa de que era ilegítimo e infundado o sacrifício da minoria civil dos cidadãos no avião. De acordo com Habermas (2012, p. 9), "o eco do imperativo categórico de Kant é evidente nessas palavras do Tribunal. O respeito à dignidade humana de cada pessoa proíbe o Estado de dispor de qualquer indivíduo apenas como meio para outro fim, mesmo se for para salvar a [vida] de muitas outras pessoas". Subjacente a isso está a ideia que a aprovação final da lei poderia implicar a instrumentalização dos indivíduos (uma relação meio-fim). Uma saída utilitarista, a saber, a maximização do bem-estar para o maior número, implicaria o sacrifício de uma minoria.

\section{CONSIDERAÇÕES FINAIS: ALGUNS ÊXITOS E LIMITES DO UTILITARISMO}

Matti Häyry, no seu livro "Liberal Utilitarianism and Applied Ethics" (1994, p. 84-87), elenca três problemas fundamentais do utilitarismo: (i) o primeiro diz respeito à justificativa dos princípios da felicidade e do altruísmo, a saber, a pergunta sobre o porquê de a felicidade ser o princípio basilar e não outro, e o porquê que devemos ser altruístas e benevolentes em renunciar (sacrificar) a nossos desejos e individualidade em prol do bem-estar da maioria e de benefícios dos outros; (ii) o segundo concerne a uma questão axiológica vinculada ao prazer e ao bem-estar. Como estes sentimentos, enquanto oriundos de valores subjetivos, podem fundamentar a moralidade? "Alguns moralistas tentaram evitar os problemas do hedonismo e do hedonismo modificado, definindo a felicidade em termos de certos valores objetivos. Entre os valores que, de acordo com esses moralistas, melhoram a qualidade da vida humana estão o refinamento, a educação, o conhecimento, o gosto, a simpatia e a benevolência"11 ( $\mathrm{p}$. 85). De todo modo, Häyry considera essa tentativa de objetivação dos valores algo complexo, haja vista a variabilidade daquilo que se pode, em termos das diferenças 
individuais e culturais, ser considerado válido como um valor objetivo; (iii) o terceiro problema diz respeito à aplicação do princípio da felicidade, se ele vale apenas para contextos específicos ou se gerais.

Tais problemas ${ }^{12}$ apontados por Häyry podem ser sintetizadas nestas duas objeções fundamentais de Sandel (2014, p. 51-55) ao utilitarismo (o de Bentham): (i) a de que ele, tomando por base o cômputo da maximização do bem-estar em detrimento de uma minoria, consiste na violação dos direitos individuais - lembre-se aqui dos exemplos dos dilemas morais supracitados, dentre eles, o da "cidade da felicidade" na qual a população de Omelas mantém a sua utilidade (a maximização do bem-estar) em detrimento da felicidade de uma criança que é mantida obliterada do convívio social em sofrimento extremo; (ii) e a de que o utilitarismo de Bentham consequentemente não contempla as diferenças individuais considerando os prazeres e os valores uniformemente, isto é, pesa os valores numa única balança como se todos tivessem a mesma natureza, sendo que em nível de vida prática as pessoas diferem em suas expectativas axiológicas, naquilo que consideram prazer, etc.

Nas páginas finais da abordagem de Sandel sobre o utilitarismo, ele apresenta a tentativa de John Stuart Mill retificar esses déficits do utilitarismo de matriz benthamiana. Com vistas à correção do primeiro déficit (a obliteração dos direitos individuais sob o cálculo da maximização do prazer para o maior número em detrimento da minoria), Mill argumenta em On Liberty (1859) em defesa da inalienabilidade da liberdade individual, tendo como base precípua a tese segundo a qual as pessoas são livres para agir do modo que lhes agradem, desde que não violem os direitos de outrem ${ }^{13}$ (SANDEL, 2014, p. 64). A ideia central é que o indivíduo é soberano e senhor de si em todas as dimensões de sua existência (corpo, consciência, vontade...). De fato, indo ao próprio On Liberty constata-se facilmente a defesa fundamental da liberdade por parte de Mill quando escreve que ela compreende três aspectos fundamentais: (i) o domínio interno da consciência; (ii) a liberdade estética e de perseguir os objetivos de vida; (iii) e a liberdade de associação com os demais desde que não se prejudique a outrem (Cf. MILL, 1998, p. 15s).

Contra o déficit ${ }^{14}$ proveniente da uniformidade de prazeres, de acordo com Sandel, Mill argumenta que o utilitarismo não pode reduzir os valores e prazeres a uma única escala, pois há prazeres e valores mais elevados do que outros trazendo, assim, para dentro do utilitarismo o aspecto qualitativo ao invés de uma métrica simplesmente quantitativa. Na visão de Sandel isso traz uma nova abordagem eficaz para dirimir alguns dilemas morais que o utilitarismo de Bentham não consegue resolver como ocorre no exemplo dos cristãos sacrificados por leões no Coliseu romano enquanto o povo se divertia. "Uma das objeções feitas ao sangrento espetáculo é que ele violava os direitos das vítimas. Mas a outra objeção é que ele proporciona prazeres perversos, em vez de prazeres nobres" (SANDEL, 2014, p. 68).

Ou seja, o redimensionamento do utilitarismo de Bentham por Mill aponta para a tese segundo a qual a estrita maximização de prazeres para o maior número de pessoas é um procedimento altamente perigoso, haja vista o risco de violação de indivíduos sacrificados; por isso, a partir de então, o utilitarismo sob esta retificação além de considerar os direitos individuais, terá de analisar os prazeres em jogo, isto é, se eles são de fato nobres ou abomináveis. Do contrário, se é tomado apenas o ponto de vista do cálculo do maior número, é possível legitimar aberrações, como assim o foi no caso da maioria nazista que sacrificou a minoria de judeus, da maioria branca que sacrificou a minoria negra, em diversos momentos da história, etc.

Esta retificação operada por Mill perante os déficits do utilitarismo foi tão radical que, Segundo Sandel (2014, p. 65), com isso Mill afasta-se das premissas do 
utilitarismo de um modo que parece romper com o mesmo, sobretudo quanto traz à tona o elemento da inviolabilidade da liberdade individual dentro de uma ideia de progresso: violar a liberdade implica barrar e interditar o progresso do indivíduo e, concomitantemente, da humanidade ${ }^{15}$. Por certo, Mill não rompeu com o utilitarismo, como sugere Sandel. Contudo, essa é a fundamental diferença estabelecida entre os dois modelos clássicos (Bentham e Mill). Em primeiro lugar, Mill segue sendo um mentalista, na esteira de Bentham, o que lhe confere um lugar distante dos utilitaristas de preferência e objetivismo, como nos ensina o professor Manfredo. A utilidade é fundamentalmente compatível com os diferentes estados mentais dos indivíduos, mesmo levando em conta prazeres qualificados como mais elevados que outros, como fez Mill. Assim, vale lembrar os três eixos centrais do utilitarismo sugeridos no início desse artigo: a associação entre felicidade e utilidade se mantém no hedonismo qualificado; o elemento teleológico consequencialista é ratificado por Mill; e, fundamentalmente, ele usa o intuicionismo contra o racionalismo stricto, algo que autoriza argumentos para a ampliação da comunidade moral para além dos indivíduos racionais, conferindo o âmbito do direito aos seres sencientes em geral. Em tal contexto, o utilitarismo de Mill também pode ser pensado como audacioso, tentando recomendar que a comunidade moral de seres racionais deve levar em consideração o esforço e empreendimento na defesa dos direitos de todos os envolvidos, e a felicidade de um tem relação com o bem-estar dos outros ${ }^{16}$. Esse recurso utilizado por Mill é muito diferente de uma mera invocação de um "ideal moral da dignidade e da personalidade humana, independente da própria utilidade”, como critica Sandel (2014, p. 71).

Ainda sobre a crítica ao utilitarismo, de acordo com Sandel no artigo "Morality and the Liberal Ideal: Must individual rights betray the common good?" (1998, p. $109 \mathrm{~s})$,

a oposição ao utilitarismo foi feita mais fortemente por Immanuel Kant. Ele argumentou que princípios empíricos, tais como a utilidade, seriam inadequados para servir de base para a lei moral. Uma total defesa instrumental da liberdade e dos direitos não apenas tornam os direitos vulneráveis, mas falha no que concerne ao respeito à inerente dignidade humana das pessoas. O cálculo utilitarista trata as pessoas como um meio para a felicidade de outrem, não como um fim em si mesmo, dignas de respeito ${ }^{17}$.

De fato, na Grundlegung zur Metaphysik der Sitten (1785), Kant tece uma crítica às éticas da felicidade ou éticas eudaimonistas ${ }^{18}$ por estas recaírem num pragmatismo e, por isso, não ser possível uma fundamentação moral a partir das mesmas, pois a felicidade não alcança a universalidade; ela é no máximo generalizada. Além disso, Kant argumenta que a felicidade é um bem natural (todos queremos e desejamos a felicidade como dissera Aristóteles na Ética a Nicômaco), mas não é um bem moral. A questão para Kant não é ser feliz, mas moralmente digno da felicidade. Felicidade não é sinônimo automático e direto de moralidade, pois um indivíduo pode ser feliz praticando atos imorais. O outro ponto da oposição radical de Kant ao utilitarismo, como bem frisou Sandel, é que na sua visão o utilitarismo incorre na instrumentalização do outro quebrando desta forma o princípio da moralidade prática, a saber, "não trates o outro simplesmente como meio, mas como fim em si mesmo". Ou seja, na maximização do prazer para a maioria sempre uma minoria é instrumentalizada e sujeitada a algum tipo de sacrifício que viola frontalmente os seus direitos fundamentais (nesse sentido, Kant é um defensor par excellence dos direitos humanos).

Há uma passagem emblemática em Antropologia de um ponto de vista 
pragmático (n. 130) onde Kant associa as correntes eudaimonistas e o utilitarismo ao egocentrismo moral, e chama os eudaimonistas de "egoístas práticos":

O egoísta moral é aquele que reduz todos os fins a si mesmo, que não vê utilidade senão naquilo que lhe serve, e também como eudemonista coloca simplesmente na utilidade e na própria felicidade, e não na representação do dever, o fundamento de determinação supremo de sua vontade. Pois cada ser humano forma conceitos diferentes sobre aquilo que considera fazer parte da felicidade, é precisamente o egoísmo que leva a não ter pedra de toque alguma do genuíno conceito de dever, que, como tal, tem de ser inteiramente um princípio de validade universal. Todos os eudaimonistas são, por isso, egoístas práticos.

Pensamos que este ponto da ruptura entre felicidade (o bem-estar) e moralidade (o justo) evocado por Kant como um possível déficit do utilitarismo foi tratado em Theory of Justice (1971, p. 25s) por Rawls. No capítulo inicial ele considera três tipos de teorias teleológicas, a saber, (i) o perfeccionismo que tem como telos a realização da excelência humana, e foi proposto de modo mais emblemático por Aristóteles e

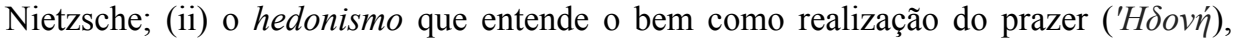
algo que se arrasta desde o epicurismo; (iii) e o eudaimonismo que entende o bem como felicidade, e tem como expoente Bentham, a versão clássica do utilitarismo. No entendimento de Rawls, essas correntes teleológicas implicam o gap entre o bem e o justo e o fazem a partir de dois equívocos fundamentais: pensam o bem a partir do apelo ao intuicionismo e ao senso comum, e depois o projetam como se fosse universalmente justo; e permitem que as pessoas avaliem o que é o bem sem se perguntar se aquilo que elas depreendem como bem é de fato justo.

Quanto aos possíveis êxitos do utilitarismo, penso que os mais evidentes concernem ao descentramento do racionalismo na moral e à defesa da igualdade de direitos entre indivíduos da mesma espécie e de espécies diferentes. O descentramento do racionalismo dá-se por meio da suplantação da categoria fundamental da moralidade: contrariando ao logocentrismo característico da filosofia ocidental, o utilitarismo não toma a "racionalidade" como instância fundamental e última da ação, mas põe no centro de sua reflexão o binômio dor e prazer, algo explícito na própria definição de utilidade entendida como maximização do bem-estar e minimização do sofrimento.

A consequência do descentramento do racionalismo ${ }^{19}$ é a quebra do especismo e julgamos que aqui reside a superioridade do utilitarismo inclusive perante o deontologismo (racionalista) kantiano. O ser humano não pode mais sentir-se superior aos demais seres porque a métrica da racionalidade já não é mais válida, e sim a métrica da capacidade de ser afetado, de sentir prazer e dor, algo que não apenas um humano, mas outros seres sencientes também podem experimentar. Nesse sentido, do mesmo modo que os humanos, os animais também são dignos de igualdade e, ipso facto, de prerrogativas como proteção ética e legal. Isso implica, em nível de Brasil, barrar urgentemente o sofrimento de animais em rodeios e vaquejadas; inclusive esta defesa dos direitos dos animais tem previsão legal no Art. $225, \S 1^{\circ}$, Inc. VII da Constituição Federal onde consta, dentre outros elementos, que são vedadas práticas que coloquem em risco, maltratem ou provoquem a extinção de animais. O problema é o seu $\S .7$ (do supracitado Art. 225 da CF) onde abre-se exceção para o uso de animais em "práticas desportivas" desde que sejam em "manifestações culturais" - e é justamente a partir deste argumento culturalista e por tabela economicista (a vaquejada como manutenção de empregos e geração de renda, etc.) que a prática continua sendo mantida sob a aprovação dos Poderes de Estado em detrimento do sofrimento de animais e da violação 
de seus direitos. Não há nada de desporto e cultural na vaquejada (algo bem semelhante ao exemplo dos cristãos devorados por leões no Coliseu romano conforme citado por Sandel - um espetáculo à custa do sofrimento de outrem).

Peter Singer num artigo intitulado "All Animals are Equal" deixa claro inclusive reportando-se a Bentham - esta vantagem do utilitarismo para a equalização de direitos, seja entre gêneros, raças, sexo, espécies. A sua tese é que a mesma lógica discriminatória que subjaz no especismo também está no racismo, no sexismo e em outras diferenças arbitrárias e, por isso, injustificadas.

$\mathrm{O}$ racista viola o princípio da igualdade, dando maior peso aos interesses dos membros de sua própria raça, quando há um choque entre seus interesses e os interesses daqueles de outra raça. Da mesma forma, o especista permite que os interesses de sua própria espécie anulem os maiores interesses dos membros de outras espécies. O padrão é o mesmo em cada caso. A maioria dos seres humanos é especista (SINGER, 1986, p. 222) ${ }^{20}$.

Portanto, recapitulando, o utilitarismo na ótica desta pesquisa e a partir da análise de Sandel, tem como aspectos negativos e limitativos do ponto de vista moral a obliteração do indivíduo (e o seu sacrifício em prol da maximização do bem-estar da maioria) e a uniformização de valores e prazeres; e como aspectos positivos o descentramento da racionalidade a partir do binômio prazer e dor, e como consequência disso a ampliação da proteção ética (e ipso facto legal) de outros animais rotulados de modo especista de não-racionais, porém sencientes.

\section{REFERÊNCIAS}

ARISTÓTELES. Ética a Nicômaco. $4^{\mathrm{a}}$ ed. Trad. Leonel Vallandro e Gerd Bornheim. São Paulo: Nova Cultural, 1987.

BENTHAM, Jeremy. Uma introdução aos princípios da moral e da legislação. $2^{\mathrm{a}}$ ed. Trad. Luiz João Baraúna. São Paulo: Abril Cultural, 1979.

BRANDT, Richard B. Two Concepts of Utility. In: The Limits of Utilitarianism. Edited by Harlan Miller and William Williams. Minneapolis: University of Minnesota Press, 1982, p. 169185.

CARVALHO, Maria Cecilia. M. O utilitarismo em foco: um encontro com seus proponentes e críticos. Florianópolis: Ed. da UFSC, 2007.

CARVALHO, Maria Cecilia M. Por uma ética ilustrada e progressista: uma defesa do utilitarismo. In: Correntes fundamentais da ética contemporânea. OLIVEIRA, Manfredo Araújo de (Org.). Petrópolis, RJ: Editora Vozes, 2000.

FOOT, Philippa. The Problem of Abortion and The Doctrine of the Double Effect. Oxford Review, n. 5, (1967).

HABERMAS, Jürgen. Sobre a constituição da Europa: um ensaio. Trad. Denilson Werle; Luiz Repa; Rúrion Melo. São Paulo: Ed. Unesp, 2012.

HÄYRY, Matti. Liberal Utilitarianism and Applied Ethics. London and New York: Routledge, 1994.

HOBBES, Thomas. Leviatã ou matéria, forma e poder de uma república eclesiástica e civil. Trad. João Paulo Monteiro, Maria Beatriz Nizza da Silva, Claudia Berliner. São Paulo: Martins Fontes, 2003.

KANT, Immanuel. À paz perpétua. Trad. Marco Zingano. Porto Alegre, RS: L\&PM, 2010.

KANT, Immanuel. Anthropologie in pragmatischer Hinsicht. In: Schriften zur Anthropologie, Geschichtsphilosophie, Politik und Pädagogie. Hrsg. von Wilhelm Weischedel. Frankfurt: Suhrkamp, 1977, v. 2.

KANT, Immanuel. Antropologia de um ponto de vista pragmático. Trad. Clélia Aparecida Martins. São Paulo Iluminuras, 2006. 
KANT, Immanuel. Grundlegung zur Metaphysik der Sitten. Hrsg. von Karl Vorländer. Hamburg: Verlag Meiner, 1965.

KANT, Immanuel. Die Metaphysik der Sitten. Band VIII. Hrsg. Wilhelm Weischedel. Frankfurt am Main: Suhrkamp, 1977, v. 2.

MILL, John Stuart. The Subjection of Women. Auckland, New Zealand: The Floating Press, 2009.

MILL, John Stuart. Utilitarianism. Auckland, New Zealand: The Floating Press, 2009.

MILL, John Stuart. On Liberty. Pennsylvania. Pennsylvania State University, 1998.

O'Neill, Onora. Autonomy, individuality and consent. Autonomy and Trust in Bioethics. Cambridge: Cambridge University Press, 2002, pp.29-48.

RAWLS, John. A Theory of Justice. Cambridge: Harvard University Press, 1971.

SANDEL, Michael. Justiça: o que é fazer a coisa certa. 16 ${ }^{\mathrm{a}}$ ed. Trad. Heloisa Matias; Maria Alice Máximo. Rio de Janeiro: Civilização Brasileira, 2014.

SANDEL, Michael. Morality and the Liberal Ideal: Must individual rights betray the common good? In: Ethische und politische Freiheit. Herausgegeben von Julian Nida-Rümelin und Wilhelm Vossenkuhl. Berlin; New York: Walter de Gruyter, 1998, p. 108-113.

SCARRE, Geoffrey. Utilitarianism. New York: Routledge, 1996.

SEN, Amartya. A ideia de justiça. Trad. Denise Bottmann; Ricardo D. Mendes. São Paulo: Companhia das Letras, 2011.

SHENG, C. L. A New Approach to Utilitarianism: A Unified Utilitarianism Theory and Its Application to Distributive Justice. Dordrecht: Springer Science \& Business Media Dordrecht, 1991.

SINGER, Peter. All Animals are Equal. In: Applied Ethics. Edited by Peter Singer. New York: Oxford University Press, 1986, p. 215-228.

SIMÕES, Mauro Cardoso. John Stuart Mill: utilitarismo e liberalismo. São Paulo: Ideias \& Letras, 2016.

SOLOMON, Robert C. O prazer da filosofia: entre a razão e a paixão. Trad. Maria Beatriz de Medina. Rio de Janeiro: Civilização Brasileira, 2011.

WILLIAMS, Bernard; SEN, Amartya. (Eds.). Utilitarianism and Beyond. Cambridge: Cambridge University Press, 1982.

\section{Notas}

1 No mesmo artigo, Cecília (2000, p. 109) inclui um tópico interessante sobre "o utilitarismo negativo" de Karl Popper. De acordo com esta versão, o foco do utilitarismo não deveria ser o de maximizar o prazer para um maior número de pessoas, mas a minimização da dor e do sofrimento de camadas marginalizadas e excluídas da sociedade. Para o leitor que se interesse pela temática filosófica do utilitarismo, há um livro organizado pela referida autora intitulado "O utilitarismo em foco: um encontro com seus proponentes e críticos" (2007).

2 Esta vinculação de Sen ao utilitarismo como propõe a autora é controversa; o próprio Sen $(2009$, p. 49) adverte que a sua teoria focada nas realizações tem uma conexão direta com o conceito de "capacidades" (Capabilities) e não com o conceito "utilidade": "[...] as realizações sociais são avaliadas com relação às capacidades que as pessoas têm, e não com relação a suas utilidades ou sua felicidade (como Bentham e outros utilitaristas recomendam)".

3 Sobre os traços comuns do utilitarismo, apesar de suas diferentes versões, escreve Richard Brandt em Two Concepts of Utility (1982, p. 169): "Utilitaristas concordaram que os atos, leis e instituições deveriam ser avaliados por suas consequências reais ou esperáveis, de uma forma ou de outra, mais particularmente por se maximizar a utilidade ou bem-estar dos seres sencientes". (Utilitarians have agreed that acts, laws, and institutions should be appraised by their actual or expectable consequences, in one way or another, more particularly by whether they maximize the utility or welfare of sentient creatures".

4 Vale lembrar que a própria concepção antagônica de "deontologia" foi criada por Bentham, justamente para se referir à fundamentação moral kantiana do "dever", o que demonstra a 
importância do resgate que o utilitarismo clássico ofereceu do consequencialismo teleológico.

5 "The creed which accepts as the foundation of morals, Utility, or the Greatest Happiness Principle, holds that actions are right in proportion as they tend to promote happiness, wrong as they tend to produce the reverse of happiness. By happiness is intended pleasure, and the absence of pain; by unhappiness, pain, and the privation of pleasure".

6 "Of all difficulties which impede the progress of thought, and the formation of well-grounded opinions on life and social arrangements, the greatest is now the unspeakable ignorance and inattention of mankind in respect to the influences which form human character".

7 No original grego, "eudaimonia" ( $\dot{u} \delta \alpha \iota \mu o v i ́ \alpha)$ significa "bom espírito", "bom gênio", ampliando-se para "bem-estar", "felicidade".

8 "A felicidade é, pois, a melhor, a mais nobre e a mais aprazível coisa do mundo" (ARISTÓTELES, 1991, livro I).

9 De acordo com Geoffrey Scarre (1996, p. 74), “o pressuposto básico do princípio da utilidade, explanado no primeiro capítulo de Introdução aos Princípios de Morais e Legislação, é que toda pessoa está sujeita ao império do prazer e da dor, os únicos determinantes do comportamento humano; o objetivo utilitário deve, portanto, ser 'reter o feitio da felicidade pelas mãos da razão e da lei' (Bentham 1789: 1). Todas as ações devem ser aprovadas ou reprovadas unicamente de acordo com sua tendência de promover ou oporse à utilidade (de outra forma, o "benefício", "vantagem", "prazer", "bom" ou "felicidade") das pessoas que afetam." (The basic presupposition of the utility principle, he explained in the first chapter of An Introduction to the Principles of Morals and Legislation, is that every person is subject to the empire of pleasure and pain, the only determinants of human behavior; the utilitarian objective must therefore be to "rear the fabric of felicity by the hands of reason and law' (Bentham 1789:1). All actions should be approved or disapproved solely according to their tendency to promote or to oppose the utility (otherwise, the 'benefit', 'advantage', 'pleasure', 'good' or 'happiness') of the persons they affect).

10 Cf. https://www.youtube.com/watch?v=CtUyyPakpCA

11 "Some moralists have tried to avoid the problems of hedonism and modified hedonism by defining happiness in terms of certain objective values. Among the values which, according to these moralists, improve the quality of human life are refinement, education, knowledge, taste, sympathy and benevolence".

12 De modo semelhante ao esboçado por Häyry, estes problemas fundamentais do utilitarismo também foram tratados por Ching-lai Sheng em A New Approach to Utilitarianism (1991, p. 16ss) a partir do qual o autor pontua cinco dificuldades centrais: (i) o entendimento nas diferentes versões do utilitarismo do que seja o princípio da utilidade; (ii) o problema axiológico da determinação dos valores e do que seja o útil a fim de orientar a prática moral dos sujeitos; (iii) o problema do gap entre egoísmo e altruísmo; (iv) o problema da distribuição em termos de justiça social; (v) o problema do conflito entre princípios e regras.

13 Este tipo de liberdade pode ser definido como "liberdade negativa" e já aparece formulado no Leviatã de Hobbes enquanto ausência de impedimentos externos para a ação, e por sua vez foi recepcionada na Rechtslehre de Kant. Portanto, não é uma novidade de Mill. De todo modo, está dentro da tradição liberal de defesa da liberdade.

14 "Mill tenta poupar o utilitarismo dessa objeção. A contrário de Bentham, ele acredita que seja possível distinguir entre os prazeres mais elevados e os mais desprezíveis - avaliar a qualidade, e não apenas a quantidade ou a intensidade, dos nossos desejos" (SANDEL, 2014, p. 68).

15 Essa aproximação feita por Mill entre particular e universal alterou seriamente a história da filosofia moral utilitarista. A baronesa O'Neill (2002, p. 29ss) vê implicações daquilo que pode ser considerado um tipo de "autonomia" do indivíduo utilitarista com implicações para as decisões no campo da bioética, por exemplo. Simões (2016, p. 27), por seu turno, sugere que o início do problema está no indivíduo, mas o objetivo de Mill se inclina para uma concepção de autonomia, universalmente aceita como mais valiosa e conectada com 
a individualidade do agente moral.

$16 \mathrm{Na}$ impossibilidade de transformar o hedonismo em algo eticamente universalizável, o utilitarismo poderia agora recorrer a uma concepção eudaimonista suficientemente generalista para atender a demanda do princípio da liberdade, pensado por Mill em $O n$ Liberty. Esse elemento político é importante, contudo foge do escopo do nosso trabalho.

12217 "The case against utilitarianism was made most powerfully by Immanuel Kant. He argued that empirical principles, such as utility, were unfit to serve as basis for the moral law. A wholly instrumental defense of freedom and rights vulnerable, but fails to respect the inherent dignity of persons. The utilitarian calculus treats people as means to the happiness of others, not as ends in themselves, worthy of respect".

18 Apenas uma formalidade literal, porém necessária. Alguns escrevem "eudemonista" em vez de

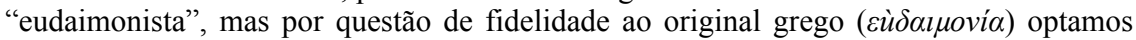
pelo último termo.

19 Sobre este descentramento do racionalismo, de acordo com Robert Solomon em O prazer da filosofia (2011, p. 125), (originalmente The Joy of Philosophy, 1999), "com certeza, o utilitarismo pode manifestar-se na compulsividade irracional (por meio do cálculo quantitativo apresentado por Jeremy Bentham...), mas, como tal, o utilitarismo serve de banal lembrete humanista de que as pessoas (e não só as pessoas) valem mais do que princípios abstratos, ainda que "racionais"".

20 The racist violates the principle of equality by giving greater weight to the interests of members of his own race, when there is a clash between their interests and the interests of those of another race. Similarly, the speciesist allows the interests of his own species to override the greater interests of members of other species. The pattern is the same in each case. Most human beings are speciesists". 